\title{
Development of the System to Support Tourists' Excursion Behavior using Augmented Reality
}

\author{
Jiawen ZHOU \\ Graduate School Student, \\ Graduate School of Information Systems, \\ University of Electro-Communications \\ Tokyo, Japan
}

\author{
Kayoko YAMAMOTO \\ Associate Professor, \\ Graduate School of Informatics and Engineering \\ University of Electro-Communications \\ Tokyo, Japan
}

\begin{abstract}
The purpose of this study is to develop an information system (AR recommended GIS) to support tourists' excursion behavior by making the accumulating, sharing, and recommending of information concerning urban tourist spots possible. The conclusion of this study can be summarized into three points as shown below. (1) In order to support tourists' excursion behaviors by integrating SNS, Twitter, Web-GIS, recommendation system, and Smart Eyeglass, in addition to making the accumulating, sharing, and recommending of information regarding urban tourist spots possible, the AR recommended GIS was designed and developed. (2) $91 \%$ were between the age of 20-40 among the 91 users, and the ultimate number of submitted information was 161. In addition, concerning the operation using Smart Eyeglass, which was conducted with tourists in the Minato Mirai area, the total number of users were 34, age of users were spread out, and all users had no experience in using Smart Eyeglasses. (3) From the results of the Web questionnaire survey, the system is compatible for the collection method of tourist spot information for users, and is mainly used to collect tourist spot information using the viewing and recommendation functions. From the results of the access analysis using the log data form during the operation, the utilization method of the system with PCs and mobile information terminals were very similar. Additionally, as the system using AR Smart Eyeglass was rated extremely highly, it was evident that it is possible to support tourists' excursion behavior using PCs, mobile information terminals, and AR Smart Eyeglasses are possible.
\end{abstract}

Keywords-Augmented Reality; Web-GIS; Social Media; Recommendation System; AR recommended GIS; Tourists' Excursion Behavior

\section{INTRODUCTION}

In recent years, regarding Japan, which has progressed in advanced information development, various information has been transmitted by means of the internet. Regarding the tourism field also, the internet transmits various information, and is the main information source for planning sightseeing tours and searching for information about tour destinations. However, because of the volume and variety of information, it has become difficult for users to appropriately select and obtain necessary information on their own. Especially for urban tourist spots, because the amount of information submitted and made public is great compared to that of regional tourist spots, and this makes it difficult for those with little knowledge or good sense of locality to efficiently obtain vital information for sightseeing, an information system to help users obtain the appropriate information is necessary.

Because small and multifunction mobile information terminals have become widespread in recent years, many can use this conveniently in their daily lives. As many urban tourist spots in Japan are mostly focused in specific areas, walking to more than one tourist spot has become mainstream. Although sightseeing plans may be changed flexibly when on foot, it is inconvenient, and can even be dangerous, to have to search for information about tourist spots on a personal assistance device, while walking on unfamiliar streets. On the other hand, as one application example of virtual reality (VR), augmented reality (AR) has recently been drawing attention, and practical application has been advancing. When using AR technology, unlike VR, regarding the reality space surrounding the user, information accumulated in virtual space can be presented. Although this technology has been used before with devices such as cellular phones, AR Smart Eyeglass and other distinctive exclusive terminals, which has been designed to be convenient, has been recently released. Accordingly, concerning sightseeing tours on foot in urban tourist spots, introduction of such AR technology in addition to existing mobile information terminals has also been anticipated.

The purpose of this study, which is based on the background as shown above, is to develop an information system (AR recommended GIS) to support tourists' excursion behavior by making the accumulating, sharing, and recommending of information concerning urban tourist spots possible. More specifically, Web-GIS, SNS, and the recommendation system will be integrated to develop a system appropriate for three information terminals including PC, mobile information terminal, and AR Smart Eyeglass, in order for the system to be available in various situations.

\section{RELATED WORK}

This study is related to 4 research areas including (1) research related to the sightseeing tour support system, (2) research related to recommendation methods of tourists spots, (3) research related to social media GIS, and (4) research related to AR. Concerning the (1) sightseeing tour support system, Kurata (2012) [1] developed an automatic sightseeing course making system using Web-GIS and genetic algorithm. Sasaki et al. (2013) [2] developed a system that collects information regarding regional resources, and supports the tours of each user. Fujitsuka et al. (2014) [3] developed an 
outing plan recommendation system using a pattern mining method that lists and extracts time series of sightseeing tours. Ueda et al. (2015) [4] developed a system to create posterior information from the action of users while sightseeing, and to support tourists' excursion behavior by sharing the aforementioned information as prior information to other users.

(2) Concerning the research related to recommendation methods of tourists spots, Uehara et al. (2012) [5] extracted tourists spot information from the Web, and proposed a system that recommends sightseeing locations by evaluating the similarities between tourist spots by means of several feature vectors. Batetel et al. (2012) [6] proposed a sightseeing location recommendation system using the multi-agent system. Shaw et al. (2012) [7] developed a system that presents a list of nearby tourist spots to users based on the location information and visit history of the user. In addition, research related to the recommendation of Point-of-Interest (POI) among research related to LSBN (Location-Based Social Networks) is also applicable to this research field. As a representative example, Ye et al. (2011) [8], Liu et al. (2013) [9], and Chen et al. (2016) [10] proposed a POI recommendation method which focuses on the user's individual attributes. Yuan et al. (2013) [11] proposed a POI recommendation method which takes into consideration time and space information using check-in data regarding LBSN.

(3) Concerning the research related to social media GIS, Yanagisawa et al. (2011) [12] in addition to Nakahara et al. (2012) [13] developed an information sharing GIS with the purpose of accumulating and sharing information regarding the local community using Web-GIS, SNS and Wiki. Yamada et al. (2013) [14] and Okuma et al. (2013) [15] developed a social media GIS which reinforced the functions of social media included in the information sharing GIS as mentioned above. By using the systems of these prior researches as a base, Murakoshi et al. (2014) [16] in addition to Yamamoto et al. (2015) [17] developed a social media GIS to support the utilization of disaster information with the assumption that it would be continually used from normal times to disaster outbreak Times. Additionally, with the social media GIS as a base, Ikeda et al. (2014) [18] developed a social recommendation GIS in order to accumulate tourist spot information and recommend it according to the taste of each user.

(4) Concerning the research related to AR, Fujimoto et al. (2014) [19] developed a navigation system within buildings by means of arrow marks using AR. Tosa et al. (2013) [20] developed a coupon use purchasing support system using AR.

However, the prior researches listed above did not propose a system that integrated the Web-GIS, SNS, recommendation system, and AR technology. In this study, by integrating the above and developing a new system, originality as a system is made evident. Additionally, the main purposes of the systems of prior researches are the accumulation and sharing of information, but lack functions that can recommend necessary information for the support for tourists' excursion behavior. In addition, with the systems of prior researches, because the access from mobile information terminals at tourist spots were not taken into consideration, real-time tourists' excursion behavior cannot be supported in a safe or effective way. Therefore, this study will develop a system to support tourists' excursion behavior that values real-time information recommendations by means of the integration of SNS, WebGIS, and the recommendation system. Additionally, by making smooth access to the system from AR Smart Eyeglasses and other various information terminals in addition to mobile information terminals possible, making sightseeing plans beforehand or searching for information at a tourist spot while touring has also become possible, and being able to obtain realtime information of tourist spots so conveniently shows the usefulness of the system.

\section{OUTLINE AND METHOD OF THIS STUDY}

This study will be conducted according to the outline and method as follows: First, the design (Section IV) and development (Section $\mathrm{V}$ ) of the AR recommendation GIS specifically for the purpose of this study will be conducted independently. Next, with the assumption that users are over 18 , the operation test and operation of the AR recommendation GIS (Section VI), in addition to evaluation and extraction of points needing improvement (Section VII) will be conducted. Here, it will be assumed that each user will use the system for a period of one month, and the operation will be conducted after the operation test and operation test evaluation is completed. In addition, the evaluation of the system will be based on the results of the Web questionnaires for users and an access analysis using the log data during the operation that will be conducted, which will make it possible to extract points needing improvements in order to help users enjoy an even more safe and successful tourists' excursion behavior.

The center of Yokohama City, Kanagawa Prefecture, was selected as the operation area. The first reason for this selection is because Yokohama is a popular urban tourist spot that has many tourists, there is an abundance of information submitted and made public, it is difficult for tourists to efficiently obtain necessary information, there are various types of tourist spots available, and a variety of tourist spots can be recommended to each user according to their taste using the system. The second reason is because walking is the main form of transportation for tourists' excursion behavior in this area. Therefore, it is appropriate to use the system for supporting those sightseeing on foot. The third reason is that there is information on a total of 200 tourist spots in the same area collected by Ikeda et al. (2014) [18], and by accumulating such information to the system in advance, the disadvantage many independent information systems have, which is not having enough data at the initial stage of operation, will be solved, and the operation of the system can be expected to be more effective.

\section{SYSTEM DESIGN}

\section{A. System configuration}

The system proposed in this study, as shown in Fig. 1, is made up of the combination of three applications including Web-GIS, SNS, and the recommendation system. Specifically, the management and visualization of submitted information on digital maps of Web-GIS, constraint of users by means of individually structured SNS, and sharing and exchanging of information between limited users have become possible, 
which enable users to submit, view and evaluate information, while grasping geographical information related to tourist spot information on digital maps. In addition, by combining recommendation systems, information that matches the tastes of each user from the accumulated and shared information can be offered by means of the digital map. Thus, even when the system is operated for a long term and the amount of accumulated information becomes massive, it is possible to direct each user to the appropriate information, and it is anticipated that it will support the efficient obtaining of tourist spot information.

Additionally, the system can be used with three information terminals including PC, mobile information terminal, and AR Smart Eyeglass. PCs are used for prior research, AR Smart Eyeglasses are used while sightseeing on foot, and mobile information terminals are used when temporarily resting. By making use of these three information terminals, the system can be used for information searches anytime from the planning stage prior to the sightseeing trip to the actual sightseeing stage, and it can be anticipated that it will effectively and safely support tourists' excursion behavior.

Therefore, the usefulness of the system stated in Section II can be explained in details as shown below.

1) Amelioration of constraints related to information searches

As one scenario of a situation where information searches become restricted, if there is an information overload when various information is submitted/transmitted, a situation where users find it difficult to select and obtain necessary information efficiently can be assumed. Therefore, to ameliorate the constraints related to such information searches, the recommendation system will be combined with the system. By doing so, among the large amount of information, it will enable users to be appropriately directed to tourist spot information according to their taste in a short period of time.

2) Amelioration of spatial constraints taking security into consideration

As one scenario of a situation where spatial constraints taking into consideration security occurs, a situation where users need information in various stages of sightseeing can be assumed. More specifically, although many use PCs for prior research before the actual sightseeing trip, there are many situations where tourist spot information may be constantly required while sightseeing. Especially when sightseeing on foot, it is inconvenient to obtain information using mobile information terminals and using such a device while walking can also be dangerous. In addition, if the information on the PC and the mobile information terminal is not synchronized, this may also cause an inconvenience. In order to ameliorate the spatial constraints while taking safety into consideration, in addition to an interface that can be used on both PCs and mobile information terminals, by introducing a AR Smart Eyeglass to support sightseeing on foot and an application dedicated to it, the system can be used in quiet situations where the user is resting or in an active situation where the user is sightseeing on foot. Thus, users will not have to rely on spatial constraints taking into consideration security while sightseeing, and by means of recommendations and viewing of appropriate tourist spot information, users can receive support for excursion behaviors.

3) Amelioration of constraints related to continuous operation

Without being restricted by time or location by means of (1) and (2) as shown above, in order to create a lasting environment where submitting, viewing, and recommending tourist spot information is possible, a design for a system that can manage submitted information is necessary. In addition, if the system is to be made so that anyone can join and there is no structure that can manage submitted information, when inappropriate information is submitted, there is a possibility that operation to serve the purpose may become difficult. However, while the system will have combined management of submitted information by means of database, because users with ill will will be found by managing accounts through SNS, this will enable the operation to be long term.

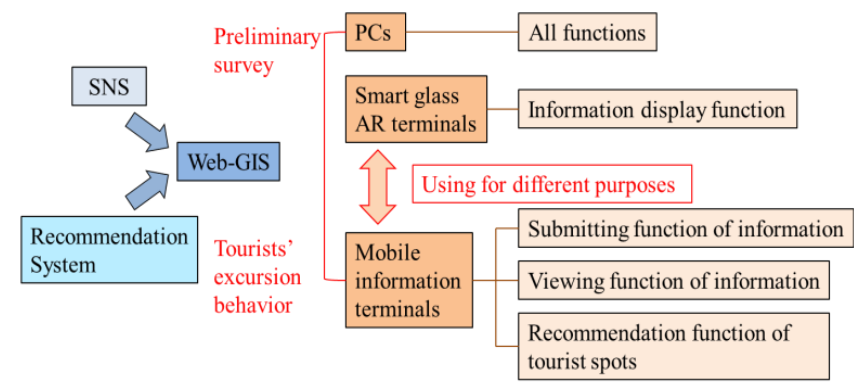

Fig. 1. System design of AR media GIS

\section{B. Outline of system design}

\section{1) System structure}

The social media GIS of this study will be developed by means of three servers including the Web server, database server, and GIS server. The Web server mainly handles the processing related to SNS and integrates each function by accessing the GIS server and the database server. SNS is implemented by JavaScript and PHP, while the recommendation system is implemented by PHP, and the database server is managed by MySQL, which accumulates collected information submitted online through SNS. The Web server and database server use the rental server from the information base center of the authors' university. The WindowsServer2008 of Microsoft is used as OS for the GIS server and ArcGISServer10.1 of ESRI is used as a GIS server software. In addition, to enable the use with AR Smart Eyeglass, an Android application using the Smart Eyeglass SDK of Sony was developed.

\section{2) Web-GIS}

In this study, ArcGISServer10.1 of ESRI was used for Web-GIS and Mapple10000 of the Shobunsha Publication Mapple digital data SHAPE edition, including detailed road network data, was used for the GIS base map of the Web-GIS. The map that will be superposed with the digital map data is, among those offered by ESRI which is compatible with API of ArcGISServer10.1, the user interface of GoogleMaps, which was the most used in prior researches in relating fields to this study. Concerning the superposing of the Mapple10000 (SHAPE edition) and GoogleMaps, while GoogleMaps used 
the new geodetic coordinates, Mapple10000 is based on the old geodetic coordinates. For this reason, using the ArcTky2Jgd, which was provided by ESRI as product support, Mapple10000 was changed to the new geodetic coordinates and changes were made in order to enable the input of information of operation areas using the ArcMap10.1.

\section{3) $\mathrm{SNS}$}

In this study, an SNS will be selected as social media to be integrated with the Web-GIS and recommendation system, and will be individually designed and developed according to its purpose. This SNS, unlike other social media, is for the purpose of designing and developing the ideal system according to the purpose of use in addition to enabling detailed system development individually according to the characteristics of the operation area. In addition, by selfmaking SNS as mentioned in section IV-A, it will enable the information transmission of the system to have a two-way direction and to integrate with the recommendation system.

First, functions related to the registration and releasing of user information in addition to submitting, viewing, and recommending information were independently designed according to the purpose of this study. Next, because it is ideal that communication between users of the system be voluntary, without designing friend registration or community functions like other SNS, comment functions, evaluation function, and sub tag functions that can be updated freely were designed as a means of communication. The comment function will be used for communication between users and to provide supplementary information to existing submissions. The evaluation function will be used by users to evaluate tourist spots on a 5-grade scale. In this way, the average of evaluation points will be shown, and in addition to providing users with this information, it can also be used as a weighting of recommendations. Additionally, the evaluation function will have a ranking function listing tourist spots in the order of the average evaluation points. Concerning sub tag functions, users will be able to easily tag a tourist spot. Because the tag shows the characteristics of the tourist spot, it can be used as a reference when doing research prior to sightseeing. Tourist spots with the same tag can also be listed.

\section{4) Recommendation system}

The recommendation system has three methods including the collaboration recommendation, content-based recommendation, and knowledge-based recommendation (Jannach et al., 2012) [21]. The knowledge-based recommendation will be used for the system. The reason for this is that it can solve the cold-start problem, which is an issue concerning the difficulties of making appropriate recommendations for new users who have just started using the system, and recommending new items introduced to the system as recommendation subjects. Kamishima (2008) [22] pointed out that there will be no problem if, regarding the former person, it is a knowledge-based recommendation and the user directly writes their own user profile, and regarding the latter person, if there is an user profile with a content-based recommendation and knowledge-based recommendation, a recommendation will not be difficult with the help of the feature vectors even with new items.
In addition, because the system is for the general public, concerning the creating of user profiles based on the user preference information, a clear and intuitive question form is ideal. Therefore, question items must be made to be answered on a five grade scale in order to create a user profile vector. Similarly, with evaluation information of tourist spots, question items must be made to be answered on a five grade scale by contributors of new tourist spot information in order to create a feature vector of tourist spots. In this way, to deal with the cold-start problem mentioned above, the system will be set so that users must input evaluation information when submitting information on tourist spots, and regarding the operation manual distributed when promoting the use of the system, the input of evaluation information aside from explaining the main purpose was requested.

Based on the created user profiles and feature vectors of tourist spots, the similarity level was calculated by means of equation (1), and the tourist spots with high similarity levels will be recommended.

$$
\begin{gathered}
\operatorname{Sim}_{j}=\frac{\sum_{i=1}^{n} U_{i} * S_{i j}}{\sqrt{\sum_{i=1}^{n}\left(U_{i}\right)^{2}} * \sqrt{\sum_{i=1}^{n}\left(S_{i j}\right)^{2}}} \\
\operatorname{Sim}_{j}: \text { Degree of similarity } \\
U_{i}: \text { User preference information } \\
S_{i j}: \text { Tourist spot evaluation information } \\
i: \text { Question information number } \\
j: \text { Tourist spot number }
\end{gathered}
$$

\section{5) Management of submitted information}

As it was mentioned concerning the amelioration of constraints related to the continuous operation in Section IV-A, design for a system that can manage submitted information is required. Therefore, with the aim to keep the operation long term, although there will be no constraints for submitted information regarding all users when released, if it is determined by the manager that the submission was written by a user with ill will, or that the submitted information is not appropriate for the purpose of the system, the system design will allow the exercising of authority to delete an account or a submission. Specifically, a function that can enable combined management of submitted information by means of database will be installed.

\section{SYSTEM DEVELOPMENT}

\section{A. System frontend}

In this study, as shown in detail below, original functions will be implemented for users in addition to the accumulating, sharing, and recommending of tourist spot information.

\section{1) Information submission function}

When submitting sightseeing information, by clicking on the "submit tourist spot information" button on the top page, users will be directed to the submitting page. Items that can be submitted include, the "title", "main tag", "description", "evaluation points of the tourist spot", and the "location information". In addition, to provide more information of the tourist spot, users can add a sub tag and upload images. After inputting and selecting the required items, if users select the tourist spot by clicking on the digital map, the location will be 
entered into MySQL and the submission will be complete after the user pushes the send button.

\section{2) Information viewing function}

On the viewing screen, tourist spots are divided into 8 categories according to the main tags, and by selecting a checkbox that each item has, the marker for tourist spots in the corresponding category can be listed on the map. By clicking the marker that the user is interested in, the title and image of the selected spot will appear in a bubble. By further clicking on the title, users will be directed to the detailed information viewing page of the selected tourist spot. On the detailed information viewing page, in addition to being able to view detailed information of tourist spots, users can evaluate and comment on the page. In this way, by enabling other users to comment on tourist spots, communication between users is promoted. Concerning the evaluation points, evaluation of tourist spots are converted to numerical values of a five grade scale, and by using the average evaluation point of multiple users, the evaluation and recommendations of tourist spots are weighted. In addition, if a tourist spot has sub tags, when users click the sub tag, they will be directed to a page where they can view other tourist spots with the same sub tag.

\section{3) Information updating function}

By clicking the information update button on the detailed information viewing page of tourist spots, users will be directed to the information update page of tourist spots. Concerning information updates, users other than the information contributor can easily add or correct information, all users can add sub tags, and edit the description. In addition, to prevent falsification that is done with ill intent, aside from locking the modifications of important information such as titles, the nicknames of editors will be recorded and disclosed on the detailed information viewing page.

\section{4) Tourist spot recommendation function}

If users would like a recommendation of tourist spots, by clicking the "tourist spots recommendation" button, users will be directed to the recommendation page. On the recommendation page, in order to improve recommendation accuracy, users can select a checkbox of tourist spot categories they would like to be recommended in. When the category is selected and sent, the top ten tourist spots according to the user's preference will be listed as the recommendation results. When users select a checkbox of a tourist spot they are interested in, the location of the spot will appear as a marker on the digital map. If the marker is clicked on and the user further clicks on the title appearing in the bubble, the user will be directed to the detailed information viewing page of the tourist spot.

\section{5) Information display function of AR Smart Eyeglass}

By entering the identification code displayed on the user information page using the Android app linked to the Smart Eyeglass, users can link their own account to the Smart Eyeglass. When sightseeing on foot, the Smart Eyeglass will present nearby tourist spot information based on the user's preference information and location information. More specifically, taking into consideration the effect on visibility, by sliding the controller, the device can switch tourist spots and display the top five spots according to the user's preference. In addition, it will display the "title", "main tag", "average evaluation points", and the "distance" of the recommended tourist spot. Additionally, by tapping the controller and selecting, the distance and direction indication to the tourist spot will be displayed in real time.

\section{6) Information management function}

Files of all user's submitted information and images are all stored on the system's database as data. The manager can manage users and check submitted information on a dedicated list screen, suspend accounts of users that have made inappropriate remarks or actions, and delete submitted information with a single click if an inappropriate submission was uploaded. Because managers are not required to confirm whether inappropriate information has been submitted within the system, the manager's burden is reduced.

\section{B. System backend}

1) Processing related to recommendations on the internet

In this study, using the knowledge-based recommendation method, the similarity level of each item is calculated with the backend and tourist spots are recommended. By registering preference information on the user information page, users can receive recommendations. More specifically, a feature vector is created with the registered preference information and the characteristics information of tourist spots, and the similarity level of user's preference information and each spot's evaluation information is calculated by means of formula (1) as shown in Section IV- B-4). In this way, the top ten tourist spots in order of the highest similarity levels are displayed as recommendation results.

\section{2) Processing related to information display on AR Smart} Eyeglass

Regarding AR Smart Eyeglass, in order for users to use it for sightseeing on foot, tourist spots that are within a walkable distance are displayed. The backend will extract nearby tourist spots with the location information of the user and display the top five spots in order of the highest similarity levels. Regarding the distance of extracting tourist spots, according to the study of the daily sphere by Ishihara et al. (2006) [23], $400 \mathrm{~m}$ is generally referred to as walking distance for normal people, acknowledged as a nearby distance in everyday life, and is defined as a distance that would not be difficult to walk to. Therefore, the system has set $400 \mathrm{~m}$ as the distance which tourist spots can be extracted. If there are less than five tourist spots within that distance for recommendations, the distance will be expanded to double and tourist spots will be extracted from within that distance. Additionally, if users are traveling, in order to lessen the load on the server which is accessed frequently in addition to taking into consideration the real time of information presentation, when users travel half the distance $(200 \mathrm{~m})$ from the center point from where the tourist spots were extracted, the similarity level will be recalculated and the tourist spot list will be updated.

\section{3) System interface}

The system has four interfaces including the PC screen of the user (Fig. 2), mobile information terminal screens (Fig. 3), screen for AR Smart Eyeglass (Fig. 4), and PC screen of managers. 


\section{OPERATION TESTS AND OPERATION}

Following the operation process of TABLE I, the operation was conducted after the operation tests/operation test evaluation of AR media GIS which was designed and developed by means of this study.

\section{A. Operation tests and operation test evaluation}

Before the operation, 6 students in their 20s were selected and a two-week operation test was conducted. From the hearing survey results of the test subjects after the operation test, three points of improvement were found in areas including the location information of tourist spots on the detailed information viewing page, the information display method on an AR Smart Eyeglass, and the updating of tourist spot information displayed on Android apps, and the system was restructured regarding these points only.

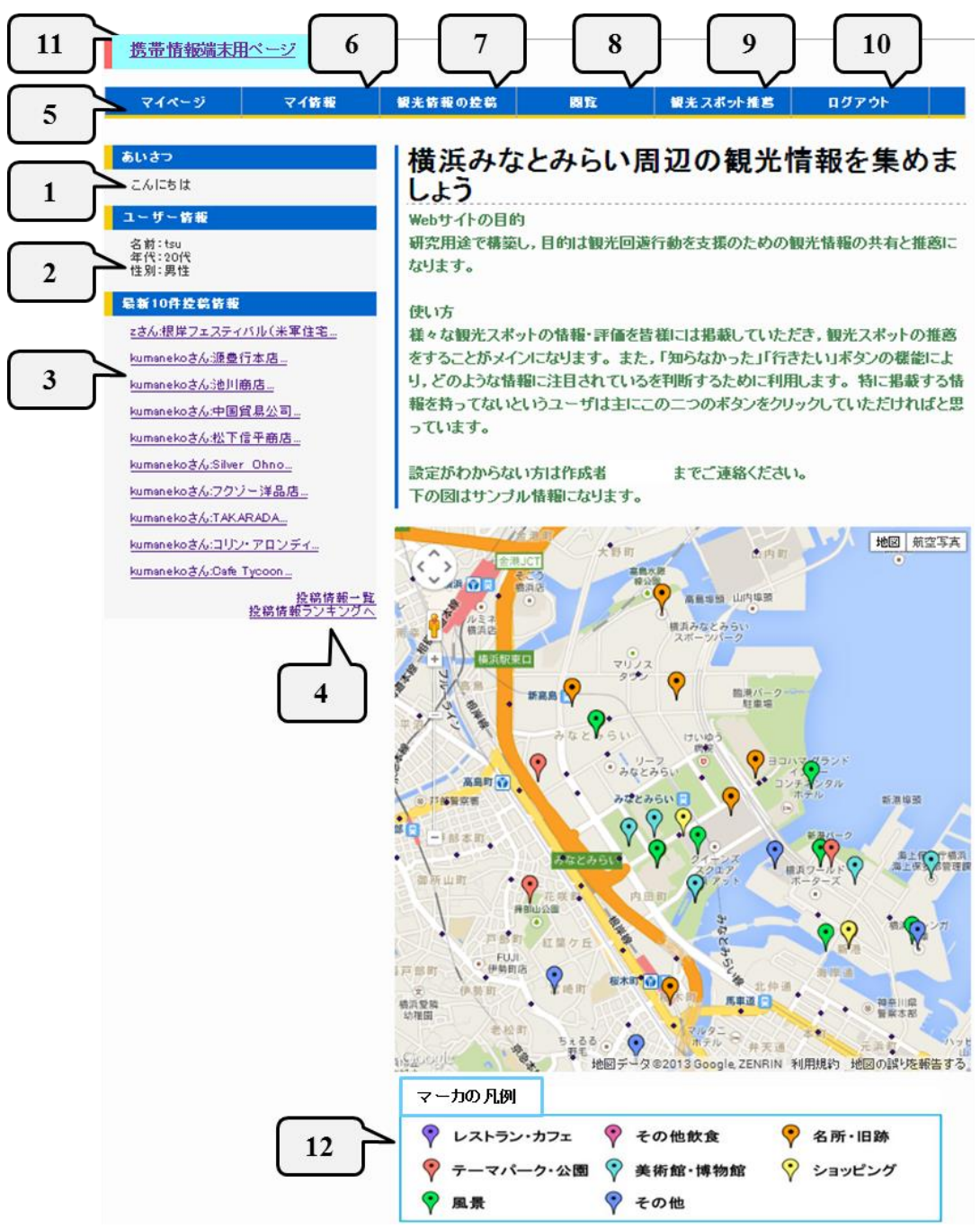

\begin{tabular}{|c|l|}
\hline No. & \multicolumn{1}{|c|}{ Description } \\
\hline 1 & User greeting \\
\hline 2 & Display of user information \\
\hline 3 & $\begin{array}{l}\text { Display of ten latest pieces of submitted tourist } \\
\text { spot information }\end{array}$ \\
\hline 4 & $\begin{array}{l}\text { Go to submitted information list and ranking } \\
\text { page }\end{array}$ \\
\hline 5 & $\begin{array}{l}\text { Go to initial page (Sample information is } \\
\text { displayed on digital map) }\end{array}$ \\
\hline 6 & $\begin{array}{l}\text { Go to user information change and registration } \\
\text { page }\end{array}$ \\
\hline 7 & $\begin{array}{l}\text { Go to page for submitting tourist spot } \\
\text { information }\end{array}$ \\
\hline 8 & $\begin{array}{l}\text { Go to page for viewing submitted tourist spot } \\
\text { information }\end{array}$ \\
\hline 9 & $\begin{array}{l}\text { Go to page where tourist spots are } \\
\text { recommended }\end{array}$ \\
\hline 10 & Logout \\
\hline 11 & Go to page for mobile information terminals \\
\hline 12 & Marker legend \\
\hline
\end{tabular}

Fig. 2. C interface and description of functions 


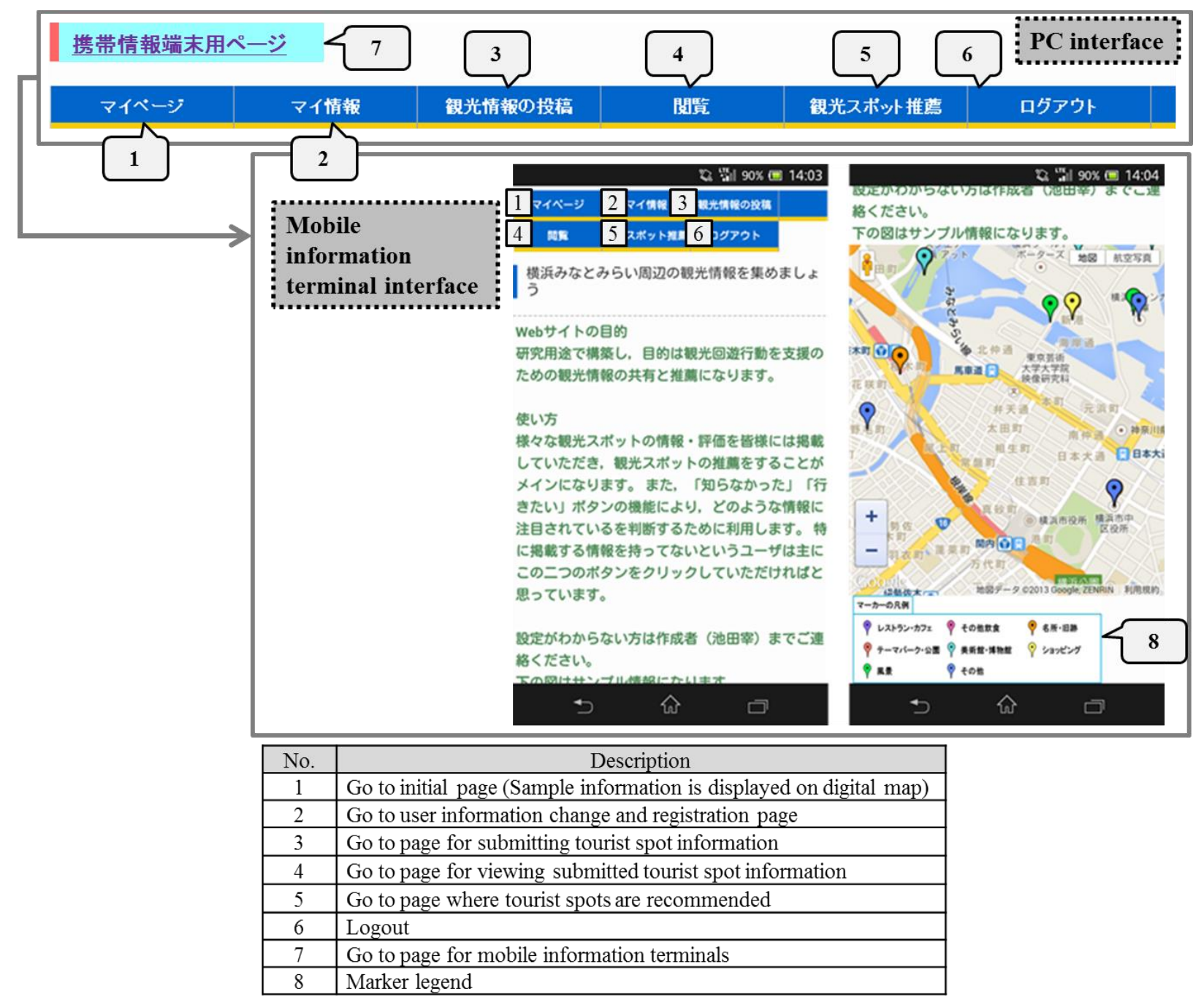

Fig. 3. Mobile information terminal interface and description of functions

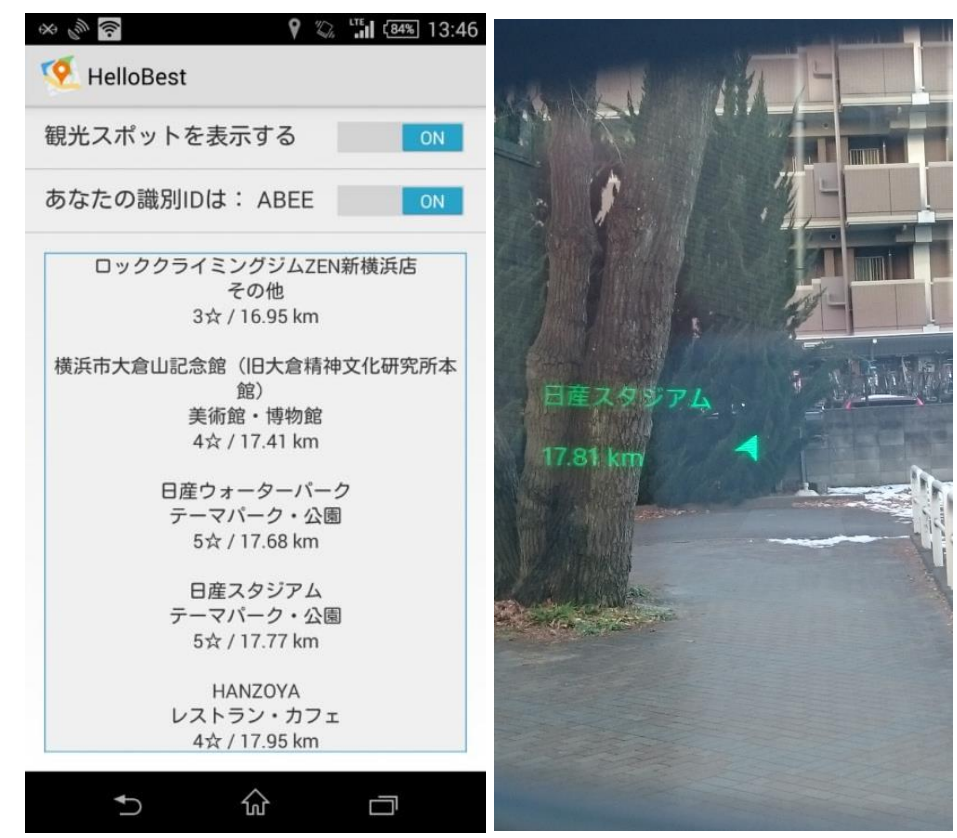

Fig. 4. Mobile information terminal interface and AR glasses terminal interface 


\section{B. Operations on the internet}

1) Summary and results of the operation

Regardless of being inside or outside the operation area, utilization was promoted through Websites of authors' laboratory, and we received cooperation by the Tourism Department of Kanagawa Prefecture and Yokohama City, and the Yokohama Convention Bureau (Yokohama Tourism Association) in distributing pamphlets and operating manuals. When accessing the system for the first time, users must register user information including "user name", "email address", "age", "gender", and "greetings" on the initial registration screen. To take into consideration those who do not want their user information made public as a profile, users can choose to enter their real name or a nickname in the "user name" box. Additionally, users can choose whether to make their "age" and "gender" public or private. When logging in after completing the initial registration, users can operate the submitting, viewing and recommending screen. In addition, by registering preference information in "My Information", each user can receive recommendations according to their tastes.

TABLE II indicates the user classification during the twomonth operation period, and Fig. 5 shows the transition of the total number of users during that time. The number of users gradually increased, and the total number was 91, with 44 being male users and 47 being female users. Users in their $20 \mathrm{~s}$ were approximately $69 \%$, users in their 30 s and 40 s were each approximately $13 \%$ and $9 \%$, and the total users in their 20 40s were approximately 91\%. As indicated in the 2015 White Paper on Telecommunications [24], the numbers shown above coincide with the fact that main users of general SNS are for the most part in their 20 40s.

2) Submitted information and use of the comment function/tag function

Fig. 5 also shows the transition of the total number of submitted items during the eight-week operation period as shown above, and it is evident that there is a significant increase in the number of submitted items from the fourth week. It can be assumed that this increase was caused as users became used to the use of the system, they actively started submitting information that they have or think is necessary around the middle of the operation period. In addition, in order to solve the cold-start problem as mentioned in Section IV-B4), the 181 tourist spot information items which were collected by Ikeda et al. (2014) [18] were prepared as initial data. As there were a total of 162 submitted items during the operation period, a total of 343 items were accumulated to the system.

TABLE III shows the submitted information regarding tourist spots according to category, and although there were many submitted information during the operation period in categories such as restaurants/cafes (65 items, approximately 40\%), shopping (29 items, approximately 18\%), and famous spots/historical sites (23 items, approximately 14\%), information was submitted in every category. In addition, almost all the submitted information had a related image submitted with it. Furthermore, with the various submissions of tourist spot information, information of tourist spots to recommend to users according to each preference, with the images attached to it, was accumulated in line with the purpose of the system.

During the operation period, the number of times the comment function was used on tourist spot information was 32, the number of times the evaluation function was used was 204, and the tag registration number was 26. From the above, among the communication methods used for the system including the comment function, evaluation function, and sub tag function, the evaluation function was the most used. The reason for this is that, while the comment function requires writing and the sub tag function requires thinking of a sub tag, the evaluation function only requires users to express their rating of tourist spots on a five grade scale.

\section{Operation using the Smart Eyeglass}

Regarding the Minato Mirai area situated in the center of the operation area, an operation using the Smart Eyeglass was conducted on December 18th targeting tourists. TABLE IV shows the user classification of the above, and the total number of users were 34 including 20 males and 14 females. When dividing users by age, although users in their 20s make up $41 \%$ of the total users which is the highest percentage, the age of users were scattered and all users had no experience using Smart Eyeglasses. After the operation, all users answered the Web questionnaire survey.

\section{EVALUATION}

In this section, based on the questionnaire survey results as summarized in TABLE II and IV, the evaluation using the Web system and Smart glass will be conducted. Next, the evaluation based on the access analysis results using the log data of the operation will be conducted. In addition, based on the evaluation results of the above, solution strategies for this system will be extracted.

\section{A. Evaluation based on the Web questionnaire survey results} of the operation on the Web

\section{1) Evaluation related to the use of the system}

a) Evaluation related to the suitability of the collection method of tourist spot information

In order to evaluate the system's suitability for tourist spot information collection methods of users, users were asked whether they used the internet to collect tourist spot information. $32 \%$ answered "often", 23\% answered "sometimes", 20\% answered "depends", 21\% answered "almost never", and 4\% answered "never". In addition, regarding the question (multiple answers) of what information terminal users use to collect tourist spot information, 84\% answered PC, and regarding mobile information terminals, $54 \%$ answered smartphone, and $14 \%$ answered tablet. In this way, from the fact that many users use two or more information terminals to collect information, information collection can be done efficiently by using each information terminal according to the situation. From the information above, it was revealed that a total of $75 \%$ of the answerers use the internet to collect tourist spot information, a total of $68 \%$ of the answered use mobile information terminals as an information terminal for information collection, and that using different 
information terminals according to the situation can make information collection more efficient. Therefore, the system, which operates with the assumption that users use different information terminals, has a fitting design for tourist spot information collection methods of users.

TABLE I. OPERATION PROCESS OF THE SYSTEM

\begin{tabular}{|c|c|c|c|}
\hline Process & Aim & Period & Specific details \\
\hline $\begin{array}{l}\text { 1. Survey of } \\
\text { present } \\
\text { conditions }\end{array}$ & $\begin{array}{l}\text { To understand efforts related to tourism in the } \\
\text { region for operation (Yokohama City) }\end{array}$ & $\begin{array}{l}\text { December } 2014 \text { - March } \\
2015\end{array}$ & $\begin{array}{l}\text { - Survey of government measures and internet } \\
\text { services } \\
\text { - Interviews with government departments } \\
\text { responsible, tourist associations, etc. }\end{array}$ \\
\hline $\begin{array}{l}\text { 2. System } \\
\text { configuration }\end{array}$ & $\begin{array}{l}\text { Configure the system in detail to suit the region for } \\
\text { operation }\end{array}$ & April - June 2015 & $\begin{array}{l}\text { - Define system requirements } \\
\text { - System configuration } \\
\text { - Create operation system }\end{array}$ \\
\hline 3. Operation test & Conduct the system operation test & July 2015 & $\begin{array}{l}\text { - Create and distribute pamphlets and operating } \\
\text { instructions } \\
\text { - System operation test }\end{array}$ \\
\hline $\begin{array}{l}\text { 4. Evaluation of } \\
\text { operation test }\end{array}$ & $\begin{array}{l}\text { Reconfigure the system based on results of } \\
\text { interviews with operation test participants }\end{array}$ & August - September 2015 & $\begin{array}{l}\text { - Evaluation using interviews } \\
\text { - System reconfiguration } \\
\text { - Amendment of pamphlets and operating } \\
\text { instructions }\end{array}$ \\
\hline 5. Operation & Carry out actual operation of the system & $\begin{array}{l}\text { October - November } \\
2015\end{array}$ & $\begin{array}{l}\text { - Appeal for use of the system } \\
\text { - Distribution of pamphlets and operating } \\
\text { instructions } \\
\text { - System operation management }\end{array}$ \\
\hline 6. Evaluation & $\begin{array}{l}\text { Evaluate the system based on the results of Web } \\
\text { questionnaires, and the results of access analysis } \\
\text { which used log data during the period of actual } \\
\text { operation }\end{array}$ & $\begin{array}{l}\text { November - December } \\
2015\end{array}$ & $\begin{array}{l}\text { - Evaluation using Web questionnaires, access } \\
\text { analysis which used log data } \\
\text { - Identification of measures for using the system } \\
\text { even more effectively }\end{array}$ \\
\hline
\end{tabular}

TABLE II. OUTLINE OF USERS AND RESPONDENTS TO THE WEB QUESTIONNAIRE

\begin{tabular}{|c|c|c|c|c|c|c|c|}
\hline & $\begin{array}{l}\text { Aged } 10 \text { to } \\
19\end{array}$ & Twenties & Thirties & Forties & Fifties & $\begin{array}{l}\text { Sixties and } \\
\text { above }\end{array}$ & Total \\
\hline Number of users (people) & 3 & 63 & 12 & 8 & 2 & 3 & 91 \\
\hline $\begin{array}{l}\text { Number of Web questionnaire respondents } \\
\text { (people) }\end{array}$ & 3 & 40 & 5 & 6 & 1 & 1 & 62 \\
\hline Valid response rate $(\%)$ & 100.0 & 63.5 & 41.7 & 75.0 & 20.0 & 33.3 & 63.3 \\
\hline
\end{tabular}

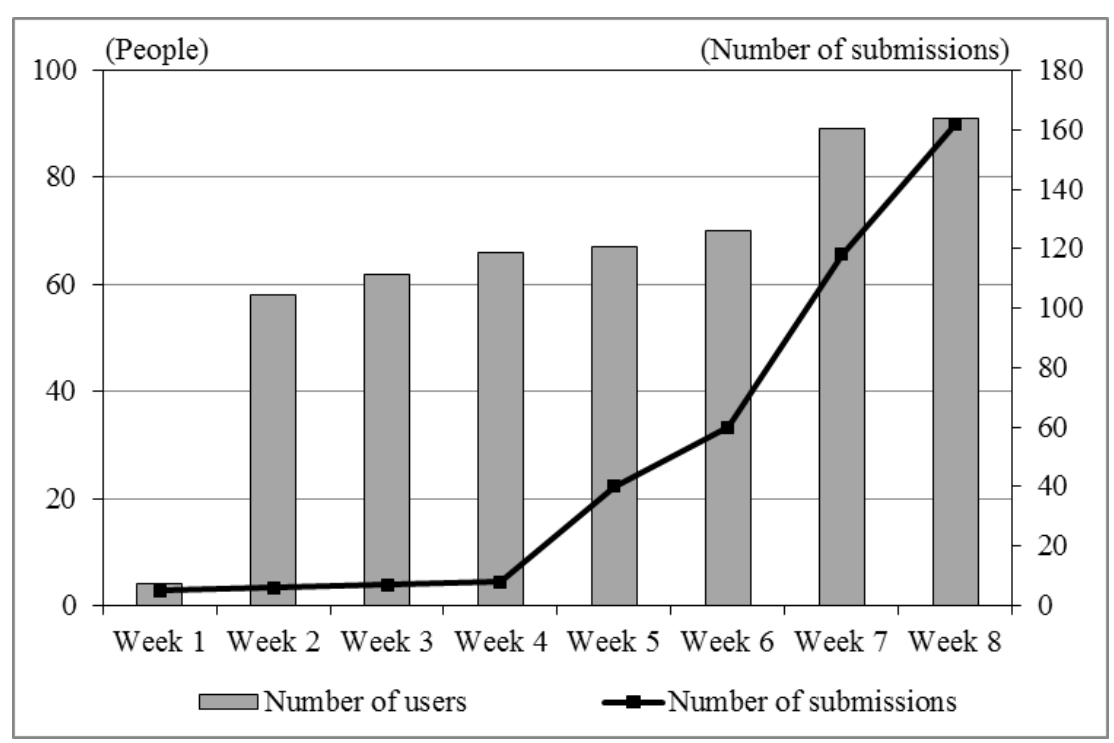

Fig. 5. Changes in the number of users and number of submissions during the operation period 
TABLE III. SUBMISSIONS OF INFORMATION, ClASSIFIED By TOURIST SPOT CATEGORY

\begin{tabular}{|l|r|r|}
\hline \multicolumn{1}{|c|}{ Category } & \multicolumn{1}{c|}{ Number of submissions } & \multicolumn{1}{c|}{ Percentage (\%) } \\
\hline Restaurants/Cafes & 65 & 40.1 \\
\hline Other eating/drinking establishments & 4 & 2.5 \\
\hline Noted places/Historic sites & 23 & 14.2 \\
\hline Shopping & 29 & 17.9 \\
\hline Theme parks/Parks & 12 & 7.4 \\
\hline Art galleries/Museums & 16 & 9.8 \\
\hline Scenery & 2 & 1.2 \\
\hline Other & 11 & 6.8 \\
\hline Total & 162 & 100.0 \\
\hline
\end{tabular}

TABLE IV. OUTLINE OF USERS AND RESPONDENTS TO THE WEB QUESTIONNAIRE

\begin{tabular}{|l|r|l|l|l|l|l|l|}
\hline & Aged 10 to 19 & Twenties & Thirties & Forties & Fifties & $\begin{array}{l}\text { Sixties and } \\
\text { above }\end{array}$ & Total \\
\hline Number of users (people) & 6 & 14 & 4 & 5 & 4 & 1 & 34 \\
\hline
\end{tabular}

b) Evaluation related to the usefulness concerning sightseeing tour activities

In order to evaluate the usefulness of the system concerning the tourists' excursion behavior of the system, users were asked about the usefulness during the actual tourists' excursion behavior in the operation area. As a result, the system was rated highly as 70\% answered "useful", $26 \%$ answered "somewhat useful", 4\% answered "neither", and no user answered negatively. Therefore, it is anticipated that the system can be useful for users during tourists' excursion behavior.

\section{2) Evaluation related to the original function of the system} function

a) Evaluation related to the use according to each

In order to evaluate the use of the system according to each function, users were presented with each function, and were asked to choose the top 2 functions that were used the most. TABLE $\mathrm{V}$ shows the percentages of chosen individual functions and the different combination of functions, and the percentages were high as $27 \%$ chose the viewing function/recommendation function, $14 \%$ chose the recommendation function/evaluation function, $11 \%$ chose the viewing function, and there were no users who used the information updating function independently. In addition, the highest percentage was $53 \%$ for the viewing function, and because it is evident that half these users use the system combining the viewing and recommendation function, it can be assumed that the system is mostly used to obtain tourist spot information.

\section{b) Detailed evaluation related to original functions}

In order to evaluate the 4 functions that show the remarkable originality of the system, users were asked related questions. As shown in Fig. 6, 89\% answered "suitable" or "somewhat suitable" regarding the suitability of the tourist spots information recommended. Therefore, calculating the similarity level based on the evaluation information of each tourist spot and the preference information registered in the "My information", the results of the recommended tourist spot information with high similarity levels with the preference information of users shows that the information was appropriate for the majority of users. The suitability of evaluation items regarding tourist spot had good results as $97 \%$ answered "suitable" or "somewhat suitable", and it can also be said that this has resulted in the high suitability of recommended tourist spots.

Regarding the usefulness of submitting tourist spot information, $89 \%$ answered "useful" or "somewhat useful", and it can be said the item setting, process, and display method when submitting tourist spot information in the system is appropriate. Concerning the usefulness of attaching sub tags to tourist spot, although 93\% answered "useful" or "somewhat useful", $7 \%$ answered "not very useful". From this information, regarding users who are not used to sub tags, it can be assumed that such users considered the sub tags used in the system as not very useful.

\section{B. Evaluation based on the Web questionnaire survey results of the operation using AR Smart Eyeglasses}

In order to evaluate the operation using AR Smart Eyeglasses, first, users were asked questions regarding the accuracy and satisfaction level for information display of AR devices, in addition to security when using AR devices. As shown in Fig. 7, 82\% answered "high" or "somewhat high" concerning the accuracy of information display on glasses, and $97 \%$ answered "high" or "somewhat high" concerning the satisfaction of information display on glasses. From the information above, it can be said that the information display on AR devices of the system is appropriate. In addition, regarding the safety when using AR terminals, 88\% answered "high" or "somewhat high". However, 3\% answered "somewhat low". The reason one answerer gave was that "as the screen is hard to see under strong lighting, users may not notice their surroundings because they're trying to focus on the screen".

Next, in the same way as Section VII.-A-1), in order to evaluate the usefulness regarding the tourists' excursion behavior of the system, users were asked whether the system was useful when actually on tourists' excursion behavior in the operation area. As a result, the system was highly evaluated as $77 \%$ answered "useful", $23 \%$ answered "somewhat useful", and there were no negative comments. Therefore, the system, 
even if the AR Smart Eyeglass is used in the operation, can be assumed to be useful during tourists' excursion behavior.

\section{Evaluation based on the access analysis results using the operation log data on the Web}

1) Access analysis summary

In this study, by conducting an access analysis using the log data collected during the operation, an evaluation focused on the access numbers and access methods will be conducted. This study will integrate the Google Analytics API with the developed program in order to conduct the access analysis. Google Analytics is a free application provided by Google, and is often used as an analysis tool. Google Analytics can be used by entering the API within the program on each page of the site, and by doing so an access log can be obtained.

\section{2) Evaluation based on the access analysis results}

First, an analysis of users' access log was conducted concerning the operation in normal mode. The total session number was $415,72 \%$ used a PC while $28 \%$ used a mobile information terminal as an information terminal in order to access the system. TABLE VI shows the number of visits to each function page, and the total number of visits was 2,846 . Concerning visits from PCs, excluding the top page, although the tourist spot recommendation function page $(8 \%)$ and viewing function page $(7 \%)$ had many visits, the difference between each function page was not so great. Concerning visits from mobile information terminals, the same tendency as visits from PCs was seen. Therefore, comparing PCs and mobile information terminals, although there is a big difference regarding the number of visits of each function page, it can be said that the usage of the system is almost similar.

TABLE V. Functions USED THE Most Frequently IN THE System (UP TO Two SELECTED)

\begin{tabular}{|c|c|c|c|c|c|c|c|c|c|c|c|c|c|}
\hline & $\begin{array}{l}\text { Submission } \\
\text { function }\end{array}$ & $\begin{array}{l}\text { Viewing } \\
\text { function }\end{array}$ & $\begin{array}{l}\text { Updating } \\
\text { function }\end{array}$ & $\begin{array}{l}\text { Rec } \\
\text { func }\end{array}$ & mendation & $\begin{array}{l}\text { Eval } \\
\text { funct }\end{array}$ & & $\begin{array}{l}\text { Submission } \\
\text { function \& } \\
\text { Viewing } \\
\text { functions }\end{array}$ & $\begin{array}{l}\text { Submission } \\
\text { function \& } \\
\text { Updating } \\
\text { functions }\end{array}$ & \multicolumn{2}{|c|}{$\begin{array}{l}\text { Submission } \\
\text { function \& } \\
\text { Recommendation } \\
\text { functions }\end{array}$} & \multicolumn{2}{|c|}{$\begin{array}{l}\text { Submission } \\
\text { function \& } \\
\text { Evaluation } \\
\text { function }\end{array}$} \\
\hline $\begin{array}{l}\text { Percentage } \\
(\%)\end{array}$ & 5.4 & 10.7 & 0.0 & & 7.1 & & 5.4 & 7.1 & 7.1 & & 3.7 & & 1.8 \\
\hline & \multicolumn{2}{|c|}{$\begin{array}{l}\text { Viewing function } \\
\text { \& Updating } \\
\text { function }\end{array}$} & \multicolumn{2}{|c|}{$\begin{array}{l}\text { Viewing function \& } \\
\text { Recommendation } \\
\text { function }\end{array}$} & \multicolumn{2}{|c|}{$\begin{array}{l}\text { Viewing function } \\
\text { \& Evaluation } \\
\text { function }\end{array}$} & \multicolumn{2}{|c|}{$\begin{array}{l}\text { Updating function } \\
\text { \& Recommendation } \\
\text { function }\end{array}$} & \multicolumn{2}{|c|}{$\begin{array}{l}\text { Updating function } \\
\& \text { Evaluation } \\
\text { function }\end{array}$} & \multicolumn{2}{|c|}{$\begin{array}{l}\text { Recommendation } \\
\text { function \& } \\
\text { Evaluation function }\end{array}$} & \\
\hline & & 1.8 & & 26.7 & & 7.1 & & 1.8 & & 0.0 & & 14.3 & \\
\hline
\end{tabular}

Suitability of tourist spots information recommended

Suitability of evalustion itmes regarding toursit spot

Usefulness of submitting tourist spot information

Usefulness of attaching sub tags to tourst spot

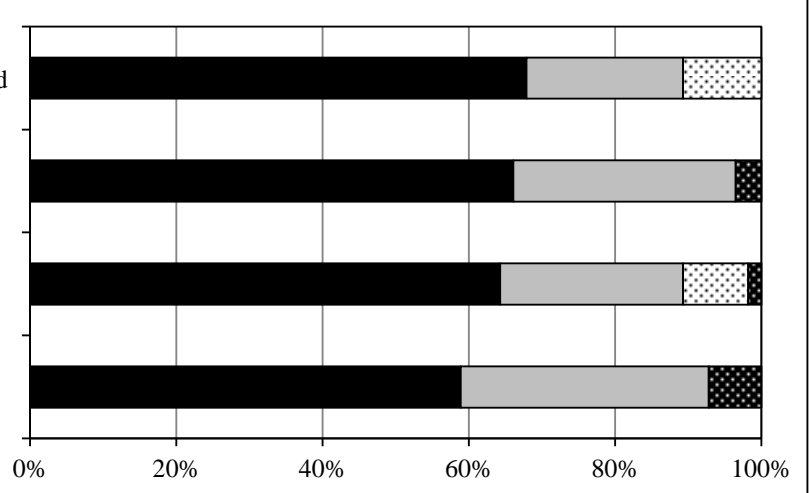

\begin{tabular}{ll|}
-Suitable/Useful & $\square$ Somewhat suitable/Somewhat useful \\
$\square$ Can't say either way & Not very suitable/Not very useful \\
$\square$ Not suitable/Not useful &
\end{tabular}

Fig. 6. Results for responses to four question items concerning original functions

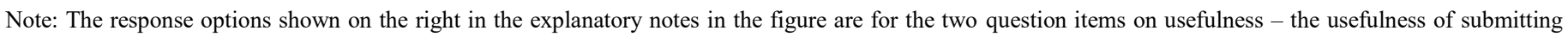
tourist spot information, and the usefulness of attaching sub tags to tourist spots. 
Accurancy of information display on glasses

Satisfaction of information disaplay on glasses

Safty when using AR terminals

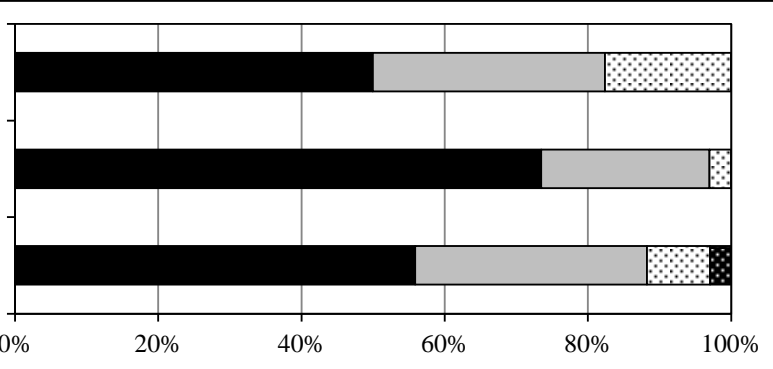

■High $\square$ Somewhat high $\square$ Can’t say eitherway somewhat low $\boldsymbol{\nabla}$ low

Fig. 7. Results for responses to accuracy and satisfaction of information display on glasses

TABLE VI. Top Five Visited Pages, Classified by INFormation Terminal used to Visit Page

\begin{tabular}{|c|c|c|c|}
\hline \multicolumn{4}{|l|}{$\mathrm{PC}$} \\
\hline Rank & Page name & Number of visits & Percentage $(\%)$ \\
\hline 1 & Initial page & 268 & 13.0 \\
\hline 3 & Recommendation page & 161 & 7.8 \\
\hline 4 & Submission page & 92 & 4.5 \\
\hline 5 & Updating page & 75 & 3.6 \\
\hline \multicolumn{4}{|c|}{ Mobile information terminals } \\
\hline Rank & Page name & Number of visits & Percentage (\%) \\
\hline 1 & Initial page & 88 & 11.1 \\
\hline 2 & Viewing page & 52 & 6.6 \\
\hline \multicolumn{2}{|l|}{ Total } & 790 & 100.0 \\
\hline
\end{tabular}

\section{Extracting solutions}

From the evaluation results of this section, solutions for the system will be summarized as follows:

\section{1) System function expansion}

Regarding the AR Smart Eyeglass, a different function other than the automatic recommendation function will be implemented. More specifically, when tourist spots that users are interested in are saved with the system on the Web, users can view the information using AR Smart Eyeglass. In addition, by implementing the routing function with the AR Smart Eyeglass, not only will tourist spots nearby be recommended, but tourist spots that users are interested, even if it is a little far, will be recommended, thereby supporting sightseeing tour activities.

\section{2) Improvement of the recommendation function}

Recommendation method that takes into consideration the time series of tourists' excursion behavior will be implemented. By doing so, the system will support not only tourist spot recommendations but also tour plans. In addition, recommendations taking into consideration each user's age, group creation, and other detailed terms, will be conducted. By means of the above, users' tourists' excursion behaviors can be supported more effectively, and planning for tourists' excursion behavior will be made more useful.

\section{CONCLUSION}

The conclusion of this study can be summarized into three points as shown below.

1) In order to support tourists' excursion behaviors by integrating SNS, Twitter, Web-GIS, recommendation system, and Smart Eyeglass, in addition to making the accumulating, sharing, and recommending of information regarding urban tourist spots possible, the AR recommended GIS was designed and developed. This made the ameliorating of information search constraints, spatial constraints taking into consideration safety, and constraints related to continuous operation possible. In addition, the Minato Mirai area, situated in the center part of Yokohama City, Kanagawa Prefecture, was selected as the operation area, and the system details were developed after field surveys were conducted.

2) Because the operation was conducted over a period of 8 weeks, an operation test was conducted 2 weeks prior to the 
operation, and the system was reconfigured by extracting points needing improvement. All subjects, whether inside or outside the operation area, were over the age of 18, and among the 91 users, $91 \%$ were between the age of 20-40. Additionally, the ultimate number of submitted information was 161. In addition, concerning the operation using Smart Eyeglass, which was conducted with tourists in the Minato Mirai area, the total number of users were 34, age of users were spread out, and all users had no experience in using Smart Eyeglasses.

3) From the results of the Web questionnaire survey given to users after the operation, the system, which sets using information terminals according to use as a premise, is compatible for the collection method of tourist spot information for users, and is mainly used to collect tourist spot information using the viewing and recommendation functions. From the results of the access analysis using the log data form during the operation, the utilization method of the system with PCs and mobile information terminals were very similar. Additionally, as the system using AR Smart Eyeglass was rated extremely highly, it was evident that it is possible to support tourists' excursion behavior using PCs, mobile information terminals, and AR Smart Eyeglasses are possible.

For research tasks in the future, points such as newly implementing functions proposed in Section VII-D in order to support tourists' excursion behaviors in a more safe and effective way, increasing usage performance by operating the system in other urban sightseeing areas, and improving the significance of use can be raised.

\section{ACKNOWLEDGMENT}

In the operation of the AR recommended GIS and the Web questionnaires of this study, enormous cooperation was received from those mainly in the Kanto region such as Kanagawa Prefecture and Tokyo Metropolis. We would like to take this opportunity to gratefully acknowledge them.

\section{REFERENCES}

[1] Y. Kurata, "Introducing a hot-start mechanism to a Web-based tour planner CT-Planner and Increasing its coverage areas", Papers and Proceedings of the Geographic Information Systems Association of Japan, Vol.21, CD-ROM, 2012.

[2] J. Sasaki, T. Uetake, M. Horikawa and M. Sugawara, "Development of personal sightseeing support system during long-term stay", Proceedings of 75th National Convention of IPSJ, pp.727-728, 2013.

[3] T. Fujitsuka, T. harada, H. Sato and K. Takadama, "Recommendation system for sightseeing plan using pattern mining to evaluate time series action", Proceedings of the Annual Conference on Society of Instrument and Control Enginnering 2014, SS12-10, pp.802-807, 2014.

[4] T. Ueda, R. Ooka, K. Kumano, H. Tarumi, T. Hayashi and M. Yaegashi, "Sightseeing support system to support generation / sharing of sightseeing information", The Special Interest Group Technical Reports of IPSJ: Information system and Social environment (IS), 2015-IS131(4), pp.1-7, 2015.

[5] H. Uehara, K. Shimada and T. Endo, "Sightseeing location recommendation using tourism information on the Web", Technical Report of The Institute of Electronics, Information and Communication Engineers, NLC, "Natural langage Understanding and Models of Communication", Vol.112, No.367, pp.13-18, 2012.
[6] M. Batet, A. Moreno, D. Sánchez, D. Isern and A. Valls, "Turist@: Agent-based personalised recommendation of tourist activities", Expert Systems with Applications, Vol.39, No.8, pp.7319-7329, 2012.

[7] B. Shaw, J. Shea, S. Sinha and A. Hogue, "Learning to rank for spatiotemporal search", Proceedings of the sixth ACM international conference on Web search and data mining, pp.717-726, 2012.

[8] M. Ye, P. Yin, W. C. Lee and D. L. Lee, "Exploiting geographical influence for collaborative point-of-interest recommendation", Proceedings of the 34th international ACM SIGIR conference on Research and Development in Information Retrieval, pp.325-334, 2011.

[9] X. Liu, Y. Liu, K. Aberer and C. Miao, "Personalized point-of-interest recommendation by mining users' preference transition", Proceedings of the 22nd ACM International Conference on Information \& Knowledge Management, pp.733-738, 2013.

[10] M. Chen, F. Li, G. Yu and D. Yang, "Extreme learning machine based point-of-interest recommendation in location-based social networks", Proceedings of ELM-2015, Vol. 2, pp. 249-261, 2016.

[11] Q. Yuan, G. Cong, Z. Ma, A. Sun and N. M. Thalmann, "Time-aware point-of-interest recommendation", Proceedings of the 36th International ACM SIGIR Conference on Research and Development in Information Retrieval, pp.363-372, 2013.

[12] T. Yanagisawa and K. Yamamoto, "Study on information sharing GIS to accumulate local knowledge in local communities", Theory and Applications of GIS, Vol.20, No.1, pp.61-70, 2012.

[13] H. Nakahara, T. Yanagisawa and K. Yamamoto, "Study on a Web-GIS to support the communication of regional knowledge in eegional communities: Focusing on regional residents' experiential knowledge", Socio- Informatics, Vol.1, No.2, pp.77-92, 2012.

[14] S. Yamada and K. Yamamoto, "Development of Social Media GIS for information exchange between regions", International Journal of Advanced Computer Science and Applications, Vol.4, No.8, pp.62-73, 2013.

[15] T. Okuma and K. Yamamoto, "Study on a Social Media GIS to accumulate urban Disaster Information: Accumulation of Disaster Information during normal times for disaster reduction measures", Socio-Informatics, Vol.2, No.2, pp.49-65, 2013.

[16] T. Murakoshi and K. Yamamoto, "Study on a Social Media GIS to support the utilization of disaster information : For disaster reduction measures from normal times to disaster outbreak times", SocioInformatics, Vol.3, No.1, pp.17-30, 2014.

[17] K. Yamamoto and S. Fujita, "Development of Social Media GIS to support information utilization from normal times to disaster outbreak times", International Journal of Advanced Computer Science and Applications, Vol.6, No.9, pp.1-14, 2015.

[18] T. Ikeda and K. Yamamoto, "Development of Social Recommendation GIS for tourist spots", International Journal of Advanced Computer Science and Applications, Vol.5, No.12, pp.8-21, 2014.

[19] A. Fujimoto, M. Niimi and H. Noda, "Development of navigation system for inside Buildings using Augumented Reality", The Institute of Electronics, Information and Communication Engineers: EMM, Multimedia Information Hiding and Enrichmen, Vol.113, No.480, pp.33-38, 2014.

[20] S. Tosa, S. Iwabuchi, S. Masuko and J. Tanaka, "Coupon use purchasing support system using the augmented reality to stimulate customers' interests", IPSJ Interaction 2013, 3EXB-36, pp.715-718, 2013.

[21] D. Jannach, M. Zanker, A. Felfernig and G. Friedrich, "Recommender systems: An introduction", Cambridge University Press, U.K., 2011.

[22] T. Kamishima, "Algorithms for recommender systems (2)", Transactions of Japanese Society of Artificial Intelligence, Vol.23, No.1, pp.89-103, 2008.

[23] H. Ishihara, T. Shimizu and Y. Izumi, "A basic study on the spheres of daily life", Urban Advance, No.45, pp.68-76, 2006.

[24] Ministry of Internal Affairs and Communications of Japan, "2015 White paper - Information and communications in Japan", Tokyo, 2 